Volume 2

Number 2 Popular Culture and Markets in

Turkey

Article 3

2017

\title{
Conducting a Communal Questionnaire in Community-Oriented Cultures
}

Forrest Watson

Bilkent University

Follow this and additional works at: https://digitalcommons.uri.edu/mgdr

Part of the Marketing Commons, and the Quantitative, Qualitative, Comparative, and Historical Methodologies Commons

\section{Recommended Citation}

Watson, Forrest (2017) "Conducting a Communal Questionnaire in Community-Oriented Cultures," Markets, Globalization \& Development Review. Vol. 2: No. 2, Article 3.

DOI: $10.23860 / M G D R-2017-02-02-03$

Available at: https://digitalcommons.uri.edu/mgdr/vol2/iss2/3

This Article is brought to you for free and open access by DigitalCommons@URI. It has been accepted for inclusion in Markets, Globalization \& Development Review by an authorized editor of DigitalCommons@URI. For more information, please contact digitalcommons-group@uri.edu. 


\section{Conducting a Communal Questionnaire in Community-Oriented Cultures}

\section{Cover Page Footnote}

I thank the MDGR editors Deniz Atik and Nikhilesh Dholakia as well as the anonymous reviewers for encouraging this work and for their constructive guidance. I also thank the owner and employees of Miss Silk's Farm for their patience and expanding my worldview. 


\section{Markets, Globalization \& Development Review}
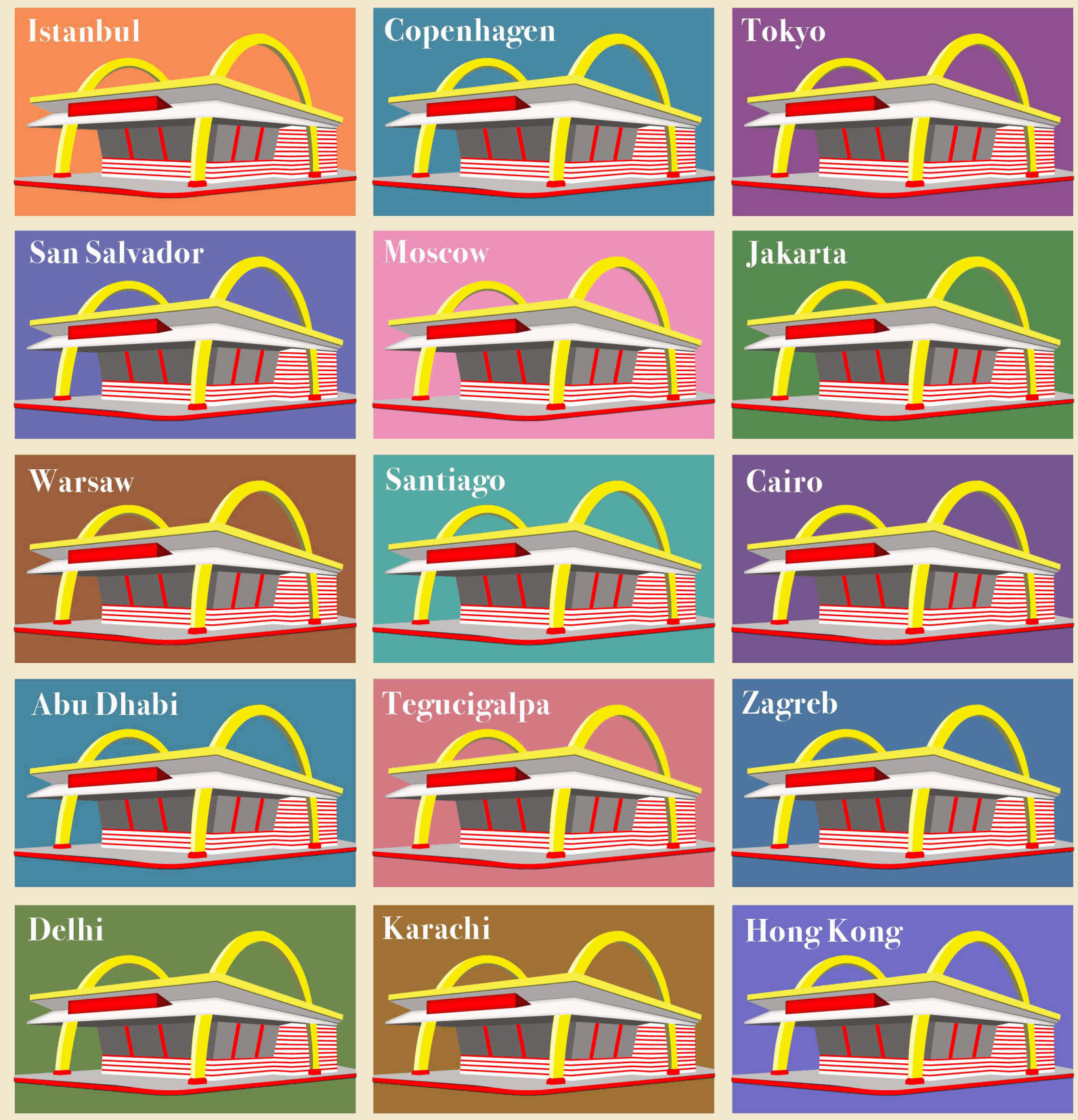

This article is available in Markets, Globalization \& Development Review: https://digitalcommons.uri.edu/mgdr/vol2/ 


\section{Conducting a Communal Questionnaire in Community-Oriented Cultures}

\section{Introduction}

Research must not divorce data collection from the realities of the cultural context. Problems arise when scholars assume a particular methodology is paramount to the social environment in which they collect data. The goal of standardization in quantitative survey research needs to be seen in the light of each context's particularities. It is important to give allowance for how reality is socially constructed and contextual, rather than see it as objective, single, and fragmentable (Hudson and Ozanne 1988).

Many have considered how to appropriately conduct research in developing contexts (Bulmer and Warwick 1993; Rudolph and Rudolph 1958; Turan 1975), even if their work is not particularly mainstream. The research methodologies that work in certain North American contexts may not be adequate for the researcher in other cultures. The individual focus of survey methodology designed and most often conducted in western countries is challenged in developing contexts that tend to be more collective in their social relationships and decision making. Researchers must give careful consideration to variation in cultural factors beyond the crude differentiation between developed and developing countries (Bulmer 1993). The "community orientation" of respondents (Turan 1975) is one particularly relevant factor that merits special consideration.

This work answers Markets, Globalization \& Development Review's call for innovative methodological approaches, agreeing that "innovative research practices do not compromise our academic standards but enrich/contribute to scholarly knowledge" (Dholakia and Atik 2016, p. 4). Indeed, this paper aims to contribute to the theme that, in order to enrich our scholarly knowledge, we also need to reevaluate and think creatively about the way in which we gather information and formulate knowledge. Our research methodologies are part of cooperating and engaging constructively with people from different communities (Schultz 2016).

A recent data collection experience in rural Turkey inspired this work. Even within Turkey there is a large disparity between the cultures of urban professionals and villagers living on the periphery, providing a fascinating case for collecting data. The context of a rural farm with mostly uneducated employees working closely together stimulated discovery (Arnould, Price and Moisio 2006). The richness and challenges of the field experience exceeded most developed context-centric training and scholarship on structured survey methodology (e.g., Sapsford 2007). I 
went to the field intending to conduct a standardized questionnaire, but had to make adjustments once I arrived. An ethnography of conducting a questionnaire in a community-oriented culture emerged from my time in the field.

Methods of cultural inquiry should allow for understanding how meanings and practices are shared or contested (Sunderland and Denny 2007). As in the body of thought at the roots of the group interview and focus group, this research considers a non-individualistic epistemology, which challenges the individual as the center of analytic attention. I see knowledge products as intersubjectively generated and not just as individual mental-events or subjectively apprehended factors (Tadajewski 2016). While my data collection experience underscores the more natural fit of qualitative interviewing in a developing context, I will discuss ways that continue to utilize mixed method and quantitative data collection techniques that apply the literature about non-individualistic epistemology.

This paper begins with a literature review of the challenges of conducting a structured survey or questionnaire in developing contexts and the special consideration of community-oriented cultures. I then explain the context of my research project and fieldwork that led me to reassess my methodology. Based on my findings, I propose a modified methodology of what I will call a communal questionnaire, and compare it to the questionnaire, qualitative interview, and focus group. I conclude with methodological suggestions for conducting research in communityoriented contexts.

\section{The Questionnaire and Challenges in Developing Contexts}

The researcher who uses a questionnaire is typically interested in individual respondents because they are members of the population described. The intended product is quantitative answers the researcher can measure and analyze to describe a population (Fowler and Mangione 1990). Questionnaires are typically "extensive" in that the researcher utilizes probability sampling, which allows inferences to be made from a small sample to a larger population. A case study method, by contrast, involves the in-depth study of a particular milieu. "Intensive methods," such as participant observation or ethnographic research, rely on a variety of methods to gain greater richness in data (Bulmer 1993).

Most large-scale questionnaires use a multiple-choice structured interview schedule that allows for rapid numerical analysis of the results (Bulmer 1993). In the developing world, questionnaires are usually conducted face-to-face and the interviewer records the answers on an interview schedule. 
In its purest form, standardization is essential in collecting quantitative data. "The goal of standardization is that each respondent be exposed to the same question experience, and that the recording of answers be the same, too, so that any differences in the answers can be correctly interpreted as reflecting differences between respondents rather than differences in the process that produced the answer" (Fowler and Mangione 1990, p. 14). As another more recent proponent put it, "Standardization lies at the heart of survey research, and the whole point is to get consistent answers to consistent questions" (Sapsford 2006, p. 7). In this paper I will address the challenges of achieving standardization.

There is of course a vast literature on survey design and implementation, but I will mention just a few of the relevant points here. By whom and the way in which questions are asked have a large effect on the data collected. Answers to survey questions are subject to response effects, or differences in survey outcomes due to procedural details. Response effects may result from issues such as understanding the question, remembering relevant information, producing an appropriate answer, and other mental processes (Tourangeau, Rips and Rasinski 2000). To deal with satisficing in question response, for example, Krosnick (1991) suggests minimizing the difficulty level of survey questions and increasing respondent motivation to expend efforts to answer survey questions. These effects are well documented and apply in all contexts. Even in the most textbook examples and westernized contexts one must apply great rigor in order to meet the demands of developing a questionnaire and properly administering it.

There are other effects that may be particularly important to consider in developing countries. As a couple of researchers venturing overseas reflected, "You undoubtedly will find yourself confronted with circumstances for which orthodox methods learned from texts and graduate courses are ill suited" (Barrett and Carson 1997, p. 90).

It cannot be assumed, especially in cultures with a communal orientation, that a survey will be conducted in private. The social desirability effect, where people tend to answer in ways approved of by others, is a concern for variability in survey data. This may be heightened when some of the people whose approval is sought are in fact present during the survey. Other people present during interviews can be referred to as "clinical witnesses" (Mitchell 1993, p. 233). In some situations this may be because people do not feel comfortable being interviewed unless others are present. In other instances this may be a reflection of a more collective culture. The presence of clinical witnesses can obviously discourage deviant or minority opinions. 
Lower education levels in developing contexts can also be a variable that makes standardization of data collection more difficult. One of the limitations in survey data is the acquiescence bias, where individuals have a greater propensity to agree with an assertion regardless of its content. The acquiescence bias is widely thought to be more prominent among respondents of lower income and education level (Narayan and Krosnick 1996), where they defer to typically higher class interviewers (Lenski and Leggett 1960). Javeline (1999) also calls attention to how the acquiescence bias can vary by culture. People of lower income and education levels may never have completed a questionnaire before, causing variation in understanding the task. Their education and literacy level may interfere with their ability to understand items on a questionnaire and their confidence to participate.

Having touched on some of the challenges for standardized data collection in developing contexts, I now review literature on a respondent's social context as a variable in conducting a questionnaire.

\section{Community Orientation}

Survey methodology typically assumes that the unit of opinion is an individual, which does not necessarily hold true in developing countries (Rudolph and Rudolph 1985). "Where life is lived more communally, opinions are likely to have a communal base" (Rudolph and Rudolph 1985 , p. 237). Turan (1975) warns of thinking primarily of the individual in research. "That the ideas of the individual are important and worth expressing is partly a cultural value. Survey research has been developed in the western world, specifically the United States, where there is a belief in the value of the ideas of the individual" (Turan 1975, p.11). The respondent in a developing context may not think of having a personal opinion in the same way someone would in the west.

Some informants may hesitate to answer a question, which feels like making a decision, something that only certain individuals in a society have a right to do (Mitchell 1993). Discussing research in developing contexts, Mitchell (1993) reflected, "Many respondents did not know what their opinion was until they had spoken to the individuals who ordinarily participated in or led the process of finding or making opinion" (p. 237). It is therefore not a given that each person has a clearly formulated individual opinion and wants to express it.

Many scholars have of course questioned the single self and called for the need to consider a person's belonging to cultures and groups. Building from the holism and level-of-analysis problem (Holt 1994), a researcher should question the assumption of an atomistic and single self, 
not just in terms of the many selves, but also how social environments influence people. The "cultural system of tastes" accounts for the cultural factors underlying consumption rather than inferring from global structures. Venkatesh (1995) made a related argument in encouraging an ethnoconsumerist perspective where the researcher looks "at the individual not just as an individual but as a cultural being, as a part of the culture, subculture, and other group affiliations" (p. 16).

Specifically reflecting on the Turkish experience, Turan (1975) refers to a type of bias he calls the "community orientation" of the respondents. In extensive surveying throughout Turkey, Turan found that Turkish people, especially in rural and isolated areas, see themselves more as part of the community than as individuals.

Turan describes two manifestations of community orientation: (1) the inclination of respondents to speak on the behalf of the collectivity to which they belong, rather than on their own behalf and (2) the "predisposition to direct interviews to the people who would be better qualified to talk in the name of the community" (p. 11). Turan theorized that the problem in both of these is that the respondents "cannot understand that it is their own opinion which is being solicited" (p. 11).

Hofstede's cultural dimensions (Hofstede 2001) also call attention to the variation in cultural values. Hofstede (2001) rates Turkey as a collectivistic society, which means that the "we" is important, and people belong to in-groups (families, clans or organizations). Harmony in the group is to be maintained and open conflicts are to be avoided. He also rates Turkey on the Feminine side of the Masculine/Feminine scale, one implication of which is a value on consensus (Hofstede 2001).

In certain societies with greater value placed in authorities, lowerclass informants may feel uncomfortable giving an opinion. This is connected to the Power dimension, which Hofstede suggests means that power is centralized and employees expect to be told what to do and rely on their superiors and rules (Hofstede 2001).

Turan notes that the identification with the community increases when the community is isolated from mainstream communications. Rather than a national value set like Hofstede espouses, Turan sees community orientation as more of a consequence of the community in which people live. He argues that as the size of a community increases, the amount of interaction with strangers increases and the community orientation declines. Based on the expansive survey administered, Turan found that urban dwellers are more confident about telling strangers their own viewpoint since relating with a stranger is a more common occurrence in their daily lives. 
The community orientation of respondents is one way that multidimensional human encounters are difficult to compress into a unidimensional market encounter (Firat 2016). In essence, many researchers compress the multiple dimensions of unique humans in diverse contexts into a quantifiable response to a statement. However, I argue that in doing so many factors and nuances, such as a villager's community orientation, are obscured. I wrestled with how to reduce the complex social dynamics and conversations into an answer to a questionnaire item with the individual as the single unit of analysis.

\section{Context and Fieldwork}

In a recent research project, I set out to measure the opinions of villagers working on a farm in western Turkey. Briefly stated, I wanted to measure the employees' level of shared commitment with the owner and customers of the farm, as well as their well-being. This data collection was part of an ongoing case study of a network of employees, customers, and owner at Miss Silk's Farm (MSF). MSF is located in Ocakli, a village in western Turkey, with fewer than 1,000 people. It is within the district of Nazilli, a town of about 150,000 people, situated in a province well known for its fertile land and agriculture. MSF employs about 100 people year-round, most of them women from the surrounding villages, with additional seasonal hires. The farm maintains approximately 50 hectares for crops and vegetables, 13,000 olive trees, 75 cows, and 500 chickens.

Based on the results of the questionnaire I conducted with employees at MSF, 79 percent of the respondents were female and about 83 percent were married. About two-thirds of the employees were between the ages of 31 and 50, with a mean age of 39 years. Just over 80 percent of the respondents had at least one child, with the mode being two children.

In Turkey, there is wide variation between development in agricultural areas and the urban centers, including social indicators such as education, especially among women. Approximately six percent of people in Turkey are illiterate, 49 percent have primary education, and 45 percent have secondary education or more (Turkish Statistical Institute 2014). At MSF, only 35 percent of the employees have more than primary education, and in interviews many said they went to school only sporadically and did not even complete primary school, which speaks to the low educational opportunities for the nearly three-quarters of respondents who grew up in a village.

Approximately 64 percent of the employees reported monthly household incomes above $1500 \mathrm{TL}$ (about \$400). Considering that the 
average monthly household income in Turkey for 2015 was 1,376 TL (Turkish Statistical Institute 2016), these employees are above average financially. These higher-than-average incomes are due to the fact that the women are both working and married, and therefore contribute to a twoincome household in most cases. Overall, it can be said that the employees of MSF, as shown in this sample, are predominantly lowereducated women, married and mothers, with household incomes above the Turkish norm.

I followed the affirmation of Flyvbjerg (2011) in utilizing mixed methods to study the individual case of MSF. I utilized an exploratory sequential design (Creswell 2015), which involved collecting and analyzing qualitative data, developing a model, and then collecting and analyzing quantitative data to test this model. The mixed method approach was the best option for my study because it allowed me to obtain a more comprehensive view and more data about shared social commitments than simply a qualitative or quantitative approach. Because this research was on shared commitments, a term that had never been conceptualized before, qualitative research was initially needed. The open-ended qualitative data collection enabled me to understand participants' experiences in context, to hear their voices, and develop a richer and more nuanced understanding of the context. The quantitative data allowed me to analyze information from a much larger sample of people, to investigate relationships in the data, and examine possible causes and effects (Creswell 2015).

During the first qualitative phase, the observations and qualitative interviews, coupled with analysis of written, visual, and online documents, helped me to understand the perspectives of the farm employees. In two previous site visits to the farm in 2014 and 2015, I conducted dozens of hours of recorded interviews that yielded hundreds of pages of transcribed text for analysis (Watson and Ekici 2017).

In the second phase, I used the results of the qualitative analysis of MSF to build a model with defined components and variables. I conducted a questionnaire among the employees (and customers) of the farm to test the conceptualization of shared commitments and their impact on wellbeing. Returning to conduct a questionnaire was another step in utilizing a repertoire of tools in a case study (Bulmer 1993). Based on my qualitative findings from the case study, I had theorized that there was an unusual level of shared commitment, or "a choice of action in common with others" (Watson and Ekici 2017), present among the actors of the farm. Utilizing the literature on commitment (Gundlach, Achrol and Mentzer 1995), I theorized three dimensions of shared commitment: (1) collective action 
(behavioral), (2) congruent values and goals (attitudinal), and (3) concern for the future welfare of others (temporal).

Based on the extensive field notes and transcripts, I developed seven to 12 items for each of the three dimensions, to measure the level of shared commitment between employees and customers and employees and the owner. The items were evaluated, pruned, and refined based on multiple independent reviewers' feedback on content validity and construct validity. This entire process took approximately 12 weeks and yielded five to eight items for each dimension.

The translation of the items from English to Turkish took another 10 weeks. Multiple independent translators reviewed each of the items, with a particular emphasis on the clarity of the items in straightforward Turkish. When translations differed, I discussed with the translators which phrasing best captured the meaning of the item. Once the translation was completed, the questions were pretested among several reviewers of different educational and socio-economic backgrounds to assess the questions.

There were 62 items on the final questionnaire and the pretests showed it would take about 15 minutes to complete verbally. There were 12 items about the employees' work at MSF, such as their length of service and their satisfaction on the job. There were five items measuring life satisfaction, using the standard satisfaction with life scale (Diener et al. 1985). The bulk of the survey was 37 items measuring three different dimensions of shared commitment (Watson and Ekici 2017) that the employees experience along with the owner and customers. The scale for all of these items was a 1 to 7 Likert scale, anchored by "I completely disagree" and "I completely agree." The survey concluded with eight demographic questions.

I went to the farm to administer the questionnaire face-to-face. Because I expected the numbers of employees at the farm to be under 100 people, I needed every questionnaire to be completed carefully in order to have enough responses for meaningful analysis. As mentioned, I was prepared that the education level of many of the women would require me to verbally read the items and record their responses (Bulmer 1993).

I employed best practices in conducting survey research in order to yield reliable and valid data. In an introduction read to the employees, I described my institution and the purpose of the research. I explained that I was entirely independent from the farm and was not working for the managers of the farm and that all responses would remain anonymous. 
The owner and managers were not present while the employees answered the questionnaire.

I encouraged the respondents to be open and honest in their answers. I emphasized that there was no right or wrong answer and that the only thing I wanted to learn was their opinion. I explained the 1 to 7 scale. As each employee answered the questions, there was in front of them an additional piece of paper with the scale printed very clearly, with each number labeled with the corresponding answers. In order to mitigate challenges in understanding my Turkish pronunciation and not to overextend myself by reading the same items over and over again, I had a recording of a female native speaker reading each of the items. In most situations I would play the recording, pausing it as necessary for the employees to have the time to circle their response for each item.

I received the approval of the owner and the other managers to conduct a questionnaire a couple of months before my site visit. I had built trust with the owner and managers in previous visits to the farm. Before going to the farm I went to great lengths to ask the managers of the farm to help me set up a schedule for conducting questionnaires with the employees. In past visits I had met with employees as they went about their jobs, but for conducting the questionnaire I requested a place where I could meet with the employees individually. I was unable to obtain a schedule before I arrived. It was not until I arrived that the managers provided me a list of employees, which was not complete or up-to-date. While the management was generally supportive of my research, they did not help me create a schedule or give me a place to meet with the employees one-on-one. I was free to meet with employees in their work spaces and break areas.

I tried to adjust my approach based on the demands of the context. Often, four or five employees who were working together were sent to me to complete the questionnaire at the same time. In these situations, I handed a copy of the questionnaire to each person. In a few situations someone told me that they were unable to complete it by themselves, and asked if I would write for them. In the findings section I will go in to greater depth about what I observed in this situation.

I completed questionnaires with 81 employees at the farm, 80 of which were usable. I had hoped there were closer to 100 employees, but the managers explained that there had been some turnover and other employees were away due to recently having a baby or various family obligations. I am only aware of two employees who insisted on not responding to the questionnaire. I took detailed field notes throughout the process and more detailed reflections as soon as I returned to the 
guesthouse at the end of each of the four days I was there. As I adapted my methodology to the unexpected contextual dynamics, I began to audio record many of the surveys and the discussions that transpired, and transcribed all of the conversations.

My subjective position as the researcher and its impact on the informants was a factor of which I was mindful (Ger and Sandikci 2006). As an American male, I stood out to everyone I interviewed as entirely "other." I was a researcher from a Turkish university, but from the capital city, which many respondents had never visited. Even before going to the site, I recognized there was a high likelihood of acquiescence in the interviews. Most of the employees were women with very little education being interviewed by a male from a higher social class (Lenski and Leggett 1960). However, my speaking imperfect Turkish helped break down some of the perceived distance. My interest in MSF and the employees' opinions seemed to give them general warmth towards me. Most of the employees had also met me in my previous visits to the farm. They are also accustomed to many customers visiting the farm, and that made me less intimidating.

Because I was so clearly different from the respondents, it may have accentuated the employees' communal orientation in wanting to have consensus in answering the questionnaire. In another sense I think my foreign identity may have been an advantage at a time when there is a high degree of polarization among Turks. Suffice it to say, my position as the researcher is another way in which standardization of data collection is dubious.

\section{Findings}

After returning from the field, I realized that I had experienced a type of ethnography as I conducted a questionnaire in, what I now call, a community-oriented context. An analysis of detailed field notes, the questionnaire results, and the transcribed conversations yielded several noteworthy findings, most strikingly the sense of a community orientation in the way respondents answered the questionnaire.

\section{Community Orientation of Respondents}

One of the primary observations I made was that the employees at the farm in rural Turkey had a very collective view of completing a questionnaire. I had in mind to meet with each of the employees individually, but in many cases this was not possible. As I reflected on the experience, analyzed the data, and compared it to the existing literature, I identified several themes related to conducting a questionnaire among 
informants with what Turan (1975) referred to as a "community orientation".

While conventional survey methodology emphasizes conducting private one-to-one surveys (e.g., Sapsford 2007), it felt much more natural to the employees and managers of the farm to have people come in groups. For example, there were four employees of the farm who worked together all day in the dairy room, making butter, cheeses, and so on. I was hoping to meet with them one at a time during their break while the others continued working, thinking this would also be more practical and less disruptive. But all four of them arrived together, ready to complete the questionnaire. It is understandable that they would want to come as a group considering that they start and end work at the same time, eat lunch, and do most work-related activities together. Many of the employees are from the same village and were hired through the personal connection and referrals of one another as the demand grew and along with it the need for more employees. They know a great deal about one another's personal lives and families, and many of the employees are related.

The employees' preference to meet with me in groups was not simply because of my being a male. While some of the women may not prefer to meet with a male alone, the male employees followed the same pattern of coming in groups.

As described above, I gave each of the employees their own questionnaire. I would typically play the audio recording of the items, pausing the recording if they needed more time to mark their answer. What surprised me was that most of the time the different groups of employees would want to discuss an item before answering it. Usually they understood the item, but they seemed interested in coming to a consensus on the proper answer. Even though I insisted that there is no "right" answer and they all might have different answers, they wanted to talk it through.

For example, a question about how often the employees see the owner or visiting customers seemed straightforward to me, but they wanted to debate this together. Partly because they work so closely together throughout the day, it seemed they felt their answers should be the same for many of the items. It was surprising too that even when I asked items that seemed more likely to vary, they still would want to discuss with one another. For example, I asked a question about whether they would work somewhere else, if they didn't work at MSF. In many instances, this question prompted discussion among the employee about their pasts, what jobs they could do, and so on. 
Typically, the most senior among the employees is a "chief" of the division in which she works. The group dynamics varied depending on how assertive the chief was, but most of the time I saw the other employees deferring to this person for their answers. The leader typically gave the final word and clarified if there was a discrepancy in opinions. This reflects the inclination of respondents with a community orientation to speak on behalf of the collective to which they belong, rather than on their own behalf (Turan 1975).

As I conducted the questionnaires, I continued to remind the informants that they could have differing opinions from one another. Seher and Kevser are two employees I met with early one morning as they rolled out dough for the bakery. Kevser is the chief of their unit, and they have worked together for about six years.

Interviewer: On some points if your ideas are not the same, you can share them. But generally I notice that your answers are the same.

Seher: Yes, because we are working together. [Kevser] is the chief at the head of our group. Because she manages everything, whatever she says, we have to do it. But we do it gladly. Our ideas are the same. If we don't agree on some points, by talking it through, we come to an understanding....

Kevser: Because the topic is customers, we have to be like-minded. Because we work together and we are in the same place. When necessary, when I am not here, the same things need to be done and agreed to.

It was striking in this dialogue to hear the employees so explicitly share why their "ideas are the same." Seher explains that they have to think the same way. Kevser affirms this, explaining that because they are working so closely together and the customers are the issue, they have to be unified in their opinions and approach. These two women laughed knowingly about how similar their answers were about living in the same village, having the same education experience, and both being married with three children. They had different answers to just three of the 37 items measuring the dimensions of shared commitment. Even though the life satisfaction questions did not directly relate to their jobs, the employees sometimes explained their answers collectively.

While there was a great deal of discussion, people did not always answer uniformly. For example, the four dairy workers who completed the survey together had about 80 percent similarity overall in their responses. On more personal items, the variation was greater. For example, there 
was an approximate 40 percent difference in how the dairy workers answered questions related to their own life satisfaction.

\section{The Least Educated Rely More on the Group}

I observed that many of the employees shied away from completing the questionnaire, not feeling that they were qualified to speak. This reflects the tendency within community orientation to direct interviews to the people who, they feel, would be better qualified to talk in the name of the community (Turan 1975). Only with great encouragement from others did they agree to participate.

The least educated employees - the ones who could not complete their own form and asked me to write their answers - were the most likely to lean heavily on their peers. In some cases they would literally try to copy all of the answers from another person in the group. I realized that the education level of these women makes it difficult to perform this task. They are more comfortable looking to a peer or leader whom they trust to have their best interest in mind (Mitchell 1993) and answer for them. In many situations, I could sense the employees were also looking to me to point them in the right direction of how they should answer.

Even within the one context of a particular farm in rural Turkey there was a large discrepancy in how surveys could be conducted. For most of the managers and employees working in the office, they wanted to answer the questionnaire silently on their own. They took ten minutes to go through the survey while sitting at their desk and returned it to me. They made it clear that they wanted to complete it independently, and to insist on asking them the questions would have been an affront to them. These employees have at minimum a high school education, some of them have attended university, and interact more frequently with customers. The discrepancy between abilities to complete the questionnaire independently is an example of how standardization in a questionnaire is very difficult to approach.

\section{Overlooked People}

Another observation was that the most timid and perhaps physically disabled people are typically underrepresented in data collection. A nonhegemonic orientation requires a concerted effort to listen to voices that would often be overlooked (Truman, Mertens and Humphries 2000). On my final day I was trying to complete interviews with the last few people on the employee list. As I sat down with one man at the lunch table, I realized he had a speech impediment. It was very difficult for him to respond to the questionnaire. It was laborious trying to repeat the questions to him and explain each of the values on the scale in order to elicit a response. The 
other employees seemed neutral as to whether or not I should have conducted the questionnaire with him. If not for the goal of completing as many surveys as possible in a limited pool of people, I would have skipped over him because the task was difficult for both of us. However, as I persevered in asking him questions, he opened up and became more assertive about his opinions and was able to express his feelings about working at the farm. I realize that a strength of a questionnaire can be the necessity to gather data from a great number of people. More generally, I believe a particular effort should be made to include data from those likely to be ignored. This experience also underscores the importance of getting informed consent, doing no harm to informants, and being sensitive to people with disabilities (Diener and Crandall 1978).

Because I was trying to complete a questionnaire with every employee on the farm, I arrived at 6:30a.m. in order to meet with night shift workers before they finished their shift. In two previous extensive qualitative research trips I had not realized there were people who clean the premises at night. I was surprised to hear the night workers' glowing reports of how much they enjoy working at the farm and how committed they feel to the owner. I see this as a more reliable testimony than what the employees who work the best hours in the most visible locations reported. I learned the value of investing extra effort to meet with more than just the most friendly and accessible people, whether they are people with disabilities or those that work the night shift. Data collection with unlikely respondents requires attention to notice the less visible people and a willingness to enter into potentially uncomfortable situations. Assertiveness to access the people who may be unintentionally or intentionally kept off limits must be balanced with ethical behavior.

\section{Permission from the Leader}

In the community-oriented culture of MSF, I observed how much people tend to defer to their leader as to whether they participate in the data collection. This applies to some extent in any culture: any employee may decline completing a questionnaire unless her boss tells her to. However, I observed that in a developing context, there are additional factors.

Most of the employees had never completed a questionnaire similar to this before, whether it was internal or from an outside researcher. The employees were apprehensive about my intentions as the researcher. I also observed reluctance due to the employees' uncertainty of their ability to do a task that seemed to require knowledge and education. Many of the people hung back because they did not want to be exposed. They were not used to being responsible for giving their own answers. 
In such a context I found it vital to have the trust of the leaders of the organization. The owner trusted me and gave me an open door with the managers, who encouraged the team leaders to have their people complete the questionnaire. Were it not for a team leader authoritatively saying, "Yes, you have to do it, it will be okay," most of the employees would not have participated.

The issue of gatekeepers is additionally important in a developing context because people are more used to deferring to authorities. Kitzinger and Barbour (1999) point out that focus groups involve increasing dependency on gatekeepers, which can be an issue if an employer is wary of employees discussing potentially divisive issues in a group. I argue that this dependency on gatekeepers is even higher in community-oriented cultures. There are important ethical considerations when working through gatekeepers to access those who are less powerful and less able to resist "voluntary" participation (Miller and Bell 2002).

\section{The Limitations of a Scale}

I also had findings that did not directly relate to the community orientation of the informants, but more generally to conducting a questionnaire in a developing context. Many of the employees struggled to grasp the idea of degree in their agreement or disagreement with an item. For example, as a warm-up question, I offered the item, "I like the color yellow." I showed them the enlarged 1 to 7 Likert scale, clearly labeled with the range of responses. As much as I tried to get informants to commit to a number on the scale, most smiled or shrugged their shoulders. For those who did answer, most would simply say they like or don't like the color. I realized it could not be taken for granted that everyone can evaluate whether they slightly agree, agree, or strongly agree with even a relatively straightforward item.

The following is an example of how I tried to push respondents toward a specific answer:

Interviewer: "My main reason for working at the farm is to earn money." [Reading Item]

Kevser: Not exactly - because why? More than just earning money, we have learned a lot here. How should I know? Trusting ourselves, how do I say it? I have learned about more important things than money since coming here. Earning money is not my only goal. 
Interviewer: So you are saying that your main reason is not to earn money. In terms of degree, what could you select?

Kevser: Which one I don't know, but initially when we first came our goal was to earn money. With time we learned that there are more valuable things than earning money. That's why I am saying this. This farm has taught us many things.

Seher: We mean that we are giving our own effort. We are earning our money but we are telling the meaning of this. "I disagree" could be the answer.

Kevser replied to the item by saying "Not exactly." She explained that learning a lot since working at the farm is about more than just money. As the interviewer, I made an effort to push her towards an answer of degree on the 1 to 7 Likert scale. Kevser replied that she didn't know, and further articulated that money was the initial motivation for working at the farm, but the reasons expanded beyond money as time continued. At this point Seher jumped in to agree with Kevser and offered a specific degree answer, "Disagree."

This excerpt is an example of how the informants are not always sure of how to answer the question by degree in terms of degrees, although they understand the essence of the item and want to articulate their reasons for it. I observed that in this context most informants preferred to discuss each item rather than just say a number. The limitation of a scale highlights the value of qualitative interviewing to obtain understanding when people want to explain themselves and struggle to define the degree. However, when wanting to measure across a larger sample of people, to investigate relationships in the data, and examine possible causes and effects (Bulmer 1993; Creswell 2015), closed-ended items are still desirable.

The use of "we" is also very prominent in the dialogue above. Kevser and Seher often speak with one voice, which was overwhelmingly the case throughout the questionnaires. Seher says, "We mean that we are giving our own effort. We are earning our money but we are telling the meaning of this. 'I disagree' could be the answer." Seher uses "we" or "our" six times in the first two sentences. Strikingly, the only time she uses "I" is when she is trying to state their answer in terms of $I$, as required by the scale.

\section{The Importance of Simplicity and Brevity}

Another lesson was to make the items as straightforward as possible, and to skip any reverse items. I knew this as I prepared the questionnaire, but 
I had to experience it first-hand to really feel the necessity of simplicity. When only answering with a degree of agreement on a Likert scale is hard, trying to get informants to grasp how to respond to reverse items was simply too taxing. By no means was this true of all the employees, but it was for the majority.

Similarly, I learned the value of keeping the questionnaire short. When an employee completed the questionnaire independently, it would only take 10 minutes. But with most of the employees, I had to read each item, pause, and often times help them understand its meaning. Frequently, there was deliberation about the answer. The questionnaire took upwards of 20 minutes when the items were discussed, and even longer in larger groups of people that wanted to discuss the items more. The five page questionnaire with 62 items felt very long to people who rarely, if ever, focus on something written for that length of time.

\section{Discussion and the Communal Questionnaire (CQ)}

My experience of trying to conduct a questionnaire on a farm in rural Turkey led me to reflect on how quantitative methodology can be applied amongst informants with a community orientation. I was confronted by the reality that an individual perspective and unit of analysis cannot be taken for granted (Turan 1975; Rudolph and Rudolph 1985). Respondents preferred to answer in groups and discuss their answers. Does a questionnaire always have to be conducted individually or can it be asked of groups of people?

My data collection experience at MSF brought me to the place of reflecting on the characteristics and goals of a questionnaire, qualitative interview, and group interview (focus group). These are not mutually exclusive and I will later consider the intersections between these techniques. Is it possible that the adapted questionnaire was in fact a qualitative interview or a focus group? In this context, I arrived at a combination of these different methods, with similarities to and differences from each. My experience in this case study situated in a communityoriented cultural context led me to adopt a hybrid methodology of what I will call the communal questionnaire (CQ). Table 1 shows a comparison of this methodology, which is a hybrid of a questionnaire, qualitative interview, and focus group.

I realized in the field that my data collection strategy was inadequate for the contextual peculiarities. As Rudolph and Rudolph pointed out more than 50 years ago, "That these [expectations upon which an opinion survey is based] are not met fully does not mean that survey work cannot be carried out in such areas, but it does mean that the 
researcher must demonstrate imagination and flexibility in his work" (1958, p. 235). I aimed to show imagination and flexibility, while grounding my approach in the existing methodological best practices.

\section{Communal Questionnaire Comparison to Questionnaire}

The $C Q$ is similar to a traditional questionnaire in that there is a large sample of respondents and a rigorously prepared set of primarily closedended questions to produce numerical data. The $C Q$ also aims to gather data to evaluate relationships.

One of the main differences, though, is that whereas a questionnaire is typically context-independent, the $\mathrm{CQ}$ is purposefully context-dependent (Hudson and Ozanne 1988). The CQ considers the intersubjectively generated nature of data (Tadajewski 2016), especially amongst groups of people with a community orientation (Turan 1975). The CQ recognizes that opinions have a communal base (Rudolph and Rudolph 1985). The individual is not just an individual but rather a cultural being who is a part of different groups and affiliations (Venkatesh 1995).

One of the ways the $C Q$ accounts for the social context is to relax the demand for a standardized one-to-one interaction in order to allow respondents to answer the questionnaire in the social group with which they naturally make their decisions and develop opinions. In my case study for example, this took the form of a husband and wife who clean together during the night shift, four employees who work together in the bakery, and six women who work together in the refrigerated storage area. While there are advantages to allowing people to respond in a way that better fits their community-oriented culture, there are of course widely recognized drawbacks of the presence of "clinical witnesses" (Mitchell 1993, p. 233) when collecting data. The respondent is not anonymous to the other people in the group, which could accentuate the social desirability effect. Divergent opinions from the group are less likely to be voiced in a group interview. The answers to the $C Q$ will reflect more of a group opinion and decision than questionnaires completed in isolation.

The $C Q$ is also different from the questionnaire in that it produces

qualitative data. Fowler and Mangione (1990) acknowledge that strict standardization is not always the appropriate methodology. For a case study, where the goal is to fully describe a particular set of individuals or organizations, less standardization in interviewing may be desirable. Follow-up questions are asked freely to obtain further information beyond the standard questionnaire. This dialogue is recorded and transcribed. 
Table 1: Comparing Communal Questionnaire with Related Methodologies

\begin{tabular}{|c|c|c|c|c|}
\hline Component & $\begin{array}{l}\text { Communal } \\
\text { Questionnaire } \\
\text { (CQ) }\end{array}$ & $\begin{array}{l}\text { Structured Survey/ } \\
\text { Questionnaire }\end{array}$ & $\begin{array}{l}\text { Qualitative } \\
\text { Interview }\end{array}$ & Focus Group \\
\hline Objective & $\begin{array}{l}\text { Quantitative and } \\
\text { Qualitative data. } \\
\text { Understanding } \\
\text { what, how often, } \\
\text { and to what } \\
\text { extent in data, } \\
\text { and relationships } \\
\text { in data; as well } \\
\text { as how attitudes } \\
\text { are developed } \\
\text { and expressed in } \\
\text { social contexts. }\end{array}$ & $\begin{array}{l}\text { Quantitative data to } \\
\text { understand what, } \\
\text { how often, to what } \\
\text { extent, and } \\
\text { relationships in } \\
\text { data; Explanation } \\
\text { (Hudson and } \\
\text { Ozanne 1988). }\end{array}$ & $\begin{array}{l}\text { Qualitative } \\
\text { data that } \\
\text { allows } \\
\text { experiences to } \\
\text { be understood } \\
\text { in context, } \\
\text { captures voice } \\
\text { of participants } \\
\text { (Creswell } \\
\text { 2015); } \\
\text { Interpretation } \\
\text { (Hudson and } \\
\text { Ozanne 1988). }\end{array}$ & $\begin{array}{l}\text { Qualitative data } \\
\text { on attitudes and } \\
\text { the process of } \\
\text { how they } \\
\text { develop and are } \\
\text { expressed } \\
\text { (Morgan and } \\
\text { Spanish 1984; } \\
\text { Kitzinger and } \\
\text { Barbour 1999) }\end{array}$ \\
\hline Perspective & $\begin{array}{l}\text { Context- } \\
\text { dependent, } \\
\text { where opinions } \\
\text { have a } \\
\text { communal base } \\
\text { (Rudolph and } \\
\text { Rudolph 1985), } \\
\text { intersubjectively } \\
\text { generated } \\
\text { (Tadajewski } \\
\text { 2016); cultural } \\
\text { beings who are a } \\
\text { part of different } \\
\text { groups } \\
\text { (Venkatesh } \\
\text { 1995) }\end{array}$ & $\begin{array}{l}\text { Positivist, Context- } \\
\text { independent } \\
\text { (Hudson and } \\
\text { Ozanne 1988). }\end{array}$ & $\begin{array}{l}\text { Interpretive, } \\
\text { Context- } \\
\text { dependent } \\
\text { (Hudson and } \\
\text { Ozanne 1988); } \\
\text { Knowledge is } \\
\text { situated and } \\
\text { contextual } \\
\text { (Mason 2002) }\end{array}$ & $\begin{array}{l}\text { Interpretive, } \\
\text { assumes a non- } \\
\text { individualistic } \\
\text { epistemology, } \\
\text { context- } \\
\text { dependent, } \\
\text { vested interests } \\
\text { and power } \\
\text { relations, } \\
\text { intersubjectively } \\
\text { generated } \\
\text { (Tadajewski } \\
\text { 2016) }\end{array}$ \\
\hline $\begin{array}{l}\text { Question } \\
\text { Preparation }\end{array}$ & $\begin{array}{l}\text { Structured } \\
\text { question } \\
\text { schedule with } \\
\text { mostly closed- } \\
\text { ended questions, } \\
\text { and some open- } \\
\text { ended questions }\end{array}$ & $\begin{array}{l}\text { Structured question } \\
\text { schedule with } \\
\text { mostly closed- } \\
\text { ended questions } \\
\text { allowing for rapid } \\
\text { numerical analysis } \\
\text { (Bulmer 1993) }\end{array}$ & $\begin{array}{l}\text { Semi- } \\
\text { structured } \\
\text { schedule of } \\
\text { mostly open- } \\
\text { ended } \\
\text { questions } \\
\text { (Mason 2002) }\end{array}$ & $\begin{array}{l}\text { Typically semi- } \\
\text { structured } \\
\text { schedule of } \\
\text { mostly open- } \\
\text { ended questions } \\
\text { (Morgan 1997) }\end{array}$ \\
\hline
\end{tabular}




\begin{tabular}{|c|c|c|c|c|}
\hline Sample & $\begin{array}{l}\text { Large, random } \\
\text { sample }\end{array}$ & $\begin{array}{l}\text { Large, random } \\
\text { sample, aims for } \\
\text { representativeness } \\
\text { (Kuzel 1992) }\end{array}$ & $\begin{array}{l}\text { Small, } \\
\text { purposive } \\
\text { sample; aims } \\
\text { for information } \\
\text { richness, } \\
\text { theory-based } \\
\text { sampling } \\
\text { (Kuzel 1992) }\end{array}$ & $\begin{array}{l}\text { Small, purposive } \\
\text { sample, perhaps } \\
\text { 3-5 groups } \\
\text { (Morgan 1997) }\end{array}$ \\
\hline Respondent(s) & $\begin{array}{l}\text { Natural social } \\
\text { units of } 2-6 \\
\text { people }\end{array}$ & Individual & $\begin{array}{l}\text { One-to-one } \\
\text { interactions, or } \\
\text { larger group } \\
\text { interviews } \\
\text { (Mason 2002) }\end{array}$ & $\begin{array}{l}\text { Ideal size is 6-8 } \\
\text { people (Krueger } \\
\text { and Casey } \\
2000) \text {. }\end{array}$ \\
\hline $\begin{array}{l}\text { Interviewing } \\
\text { technique/Rese } \\
\text { arch } \\
\text { relationship }\end{array}$ & $\begin{array}{l}\text { Move through } \\
\text { schedule, but } \\
\text { allow informants } \\
\text { to discuss and } \\
\text { expand on } \\
\text { answers. }\end{array}$ & $\begin{array}{l}\text { Move through } \\
\text { schedule, emphasis } \\
\text { on } \\
\text { standardizationwith } \\
\text { consistent answers } \\
\text { to consistent } \\
\text { questions (Sapsford } \\
\text { 2006), Dualism and } \\
\text { separation (Hudson } \\
\text { and Ozanne 1988). }\end{array}$ & $\begin{array}{l}\text { Interactional } \\
\text { exchange of } \\
\text { dialogue, a } \\
\text { relatively } \\
\text { informal style, } \\
\text { with a fluid } \\
\text { and flexible } \\
\text { structure } \\
\text { (Mason 2002) } \\
\text { Interactive, } \\
\text { cooperative } \\
\text { (Hudson and } \\
\text { Ozanne 1988). }\end{array}$ & $\begin{array}{l}\text { Carefully } \\
\text { planned and } \\
\text { moderated } \\
\text { series of } \\
\text { discussions in a } \\
\text { permissive, non- } \\
\text { threatening } \\
\text { environment } \\
\text { (Krueger and } \\
\text { Casey 2000) }\end{array}$ \\
\hline Method & $\begin{array}{l}\text { Face-to-face, in } \\
\text { natural context }\end{array}$ & $\begin{array}{l}\text { Face-to-face, } \\
\text { telephone, or online }\end{array}$ & $\begin{array}{l}\text { Face-to-face, } \\
\text { often times in } \\
\text { context }\end{array}$ & $\begin{array}{l}\text { Face-to-face, } \\
\text { typically in an } \\
\text { unnatural setting } \\
\text { (Morgan and } \\
\text { Spanish 1984) }\end{array}$ \\
\hline Product Yielded & $\begin{array}{l}\text { Completed } \\
\text { questionnaire for } \\
\text { each participant, } \\
\text { recorded } \\
\text { observations, } \\
\text { and transcribed } \\
\text { text of dialogue }\end{array}$ & $\begin{array}{l}\text { Completed } \\
\text { questionnaire for } \\
\text { each participant }\end{array}$ & $\begin{array}{l}\text { Recorded } \\
\text { observations, } \\
\text { and } \\
\text { transcribed } \\
\text { text of } \\
\text { dialogue }\end{array}$ & $\begin{array}{l}\text { Recorded } \\
\text { observations, } \\
\text { and transcribed } \\
\text { text of dialogue }\end{array}$ \\
\hline $\begin{array}{l}\text { Primary Unit of } \\
\text { Analysis }\end{array}$ & $\begin{array}{l}\text { Group and } \\
\text { individuals } \\
\text { relating within a } \\
\text { group }\end{array}$ & $\begin{array}{l}\text { Individual for } \\
\text { generalizations to } \\
\text { whole }\end{array}$ & $\begin{array}{l}\text { Individual } \\
\text { (within a } \\
\text { culture, group, } \\
\text { etc.) }\end{array}$ & Group \\
\hline
\end{tabular}


In addition to the completed questionnaires, the researcher utilizing the $C Q$ observes and takes notes on the way the respondents relate to one another and how questions are interpreted. The CQ has commonality with what has been called "cognitive pretesting" (Bickart and Felcher 1996), where respondents are asked to "think aloud" while answering questions. As my time in the field continued, I ended up recording the dialogue as the employees completed the questionnaire, capturing their thoughts about the items as I went along. Most of the employees did not simply offer a value from 1 to 7 as I expected, but instead talked about each item and why they agreed or disagreed. This adds a richness that a numeric value cannot capture. In other situations, I had my voice recorder ready to hear respondents' additional thoughts as soon as the questionnaire concluded. Whereas cognitive pretesting is conducted individually and the unit of analysis is the individual, the CQ allows for the social relating of multiple people.

Based on my findings, I question the possibility of standardization in a questionnaire (Fowler and Mangione 1990; Sapsford 2006), at least in a context like MSF. Even if the questions are standardized and the interviewer is disciplined, the situational factors that exist in a communityoriented context make it very difficult to claim standardization.

Therefore, the $\mathrm{CQ}$ does not emphasize standardization. Even within one work site I found it nearly impossible to standardize the way I conducted the survey. Some people were insistent they respond on their own, whereas others were unable to do so. My findings while attempting to conduct a standardized questionnaire in the context made it clear to me that people are not standard. I could not conduct the questionnaire with someone who struggles with literacy in the same way that I did with the other employees. A standardized survey assumes a more objective and distanced data collection approach, but based on my findings, this will tend to exclude people who are less able to respond to a standardized methodology.

But more than the variation in respondents, what stood out most was the virtual impossibility of standardizing the social component of the questionnaire. As described in detail in my findings, the presence of "clinical witnesses" (Mitchell 1993) was ubiquitous. The respondents discussed the answers with one another, much like I believe they do in their everyday work and social lives.

The $C Q$ does still affirm the value of conducting a questionnaire. Although it was extremely challenging and the data collection went differently than expected, there were still favorable outcomes from the questionnaire. The questionnaire gave me the opportunity to gather data 
from a greater breadth of employees than I had done only with lengthy qualitative interviews. In addition to motivating me, the need to reach a high number of respondents pushed the managers at the farm to help me talk with as many people as possible. I was exposed to and learned from new ideas and perspectives that I otherwise would not have.

The CQ differs somewhat from the traditional questionnaire, however, in gathering qualitative data from typically silent voices. Completing the questionnaire with the night shift workers and someone with a speech impediment proved to be a rich resource of data. However, these were also some of the most inconvenient and time-consuming surveys. The CQ encourages the extensive thrust of the survey approach, while valuing the intensive aspect of the qualitative approach (Bulmer 1993). I argue that the CQ adds to the quantitative dimension a nonhegemonic orientation where we make the effort to listen to voices that are often times overlooked (Truman, Mertens and Humphries 2000).

The quantitative data I generated is also a valuable product. While most of this paper has acknowledged some of the limitations and biases in the data, I believe that it still represents a best effort. It helps to have quantified details on employees of the farm, more detailed in fact than the farm has on its own workforce. It is also valuable to have numerical data for triangulation of my other data sources. For example, based on the qualitative interviews, I had an inflated view of the level of contact employees have with the customers, partly because, as mentioned, I was naturally talking with the employees who interface most with the customers. In doing the questionnaire I found that only 56 percent of employees have contact with customers more than once a month. I have the data now to help test the dimensions of shared commitment. This will need to be triangulated with my qualitative data and critiqued in light of the lack of standardization. Just as focus groups can be used in conjunction with surveys and qualitative interviews (Morgan 1997), so too can the CQ be used in various ways with other methods.

One of the challenges I experienced in the context was whether it made sense to have each respondent complete their own questionnaire or complete a single one for the group. As was described in the findings, there was a very high correlation in the answers. However, the answers varied by about 20 to 40 percent, meaning that a great deal of variability would be lost if only one questionnaire was completed for the group. Personal questions about work history and life satisfaction naturally differed the most. In a few groups there was a strongly dissenting voice, and this person was able to show this in her answers. I maintain there is value in each respondent completing a separate questionnaire because it 
best captures the way that opinions are formed based on the influence of the social group, but people typically still make their own final decisions.

\section{Communal Questionnaire Comparison to Focus Group}

As shown in Table 1, the CQ has a similar objective to the focus group: they both explore how points of view are intersubjectively generated (Tadajewski 2016) and expressed (Kitzinger and Barbour 1999). They both acknowledge that opinions have a communal base (Rudolph and Rudolph 1985).

Focus groups are "a dynamic and highly versatile technique" (p. 265), with many different variations. In the analytic or cultural and linguistic approach to focus groups, the emphasis is on consumer culture and consumption rather than on the individual (Catterall and Maclaran 2006). The interaction in a focus group is a way of gaining access to shared meanings such as what is taken for granted, and what other participants in groups challenge. This is also true of the CQ.

While focus groups are typically composed of strangers, there are also "friendship groups" or "mini-groups" (Catterall and Maclaran 2006, p. 264). These are more similar to the $C Q$ because people are together in their normal working or social units. Whereas a weakness of the focus group is that groups are typically brought together out of their normal context (Morgan and Spanish 1984), the CQ allows for people to be in their normal social units and context. For example, I met with some employees as they worked and with others in their typical spaces for taking a break. Because people do not have to be forced to be alone, it allows for people to stay within their normal context.

The role of the moderator in a focus group can be one of low or high involvement (Morgan 1997). The interviewer in a CQ can be considered high involvement, moving through many items in a structured questionnaire in order to generate numerical data. The interviewer allows the person to think aloud and discuss the questions with the other respondents present, interjecting follow-up questions as appropriate, but generally moving through the questionnaire. Of course, the $C Q$ can be as flexible as the researcher desires and has time for.

One of the realities of both focus groups and the $C Q$ is that the researcher "should consider how the group context and broader cultural and institutional features operate to encourage or suppress the expression of a certain point of view" (Kitzinger and Barbour 1999, p. 6). If a questionnaire is being completed amongst a group of informants, the suppression of a certain point of view must be considered. What dissenting opinions were mentioned but overruled by the rest of the group? 
The concept of "groupthink" has also been employed to explain the compliance that can occur in focus groups. Janis (1982) argues that highly cohesive groups try and maintain consensus on key issues and ignore challenges to this consensus. This is especially relevant in cultures that have a higher value on consensus (Hofstede 2001).

The focus group and $C Q$ differ, however, in that the $C Q$ will typically have a much larger sample size with structured, closed-ended questions, which will also generate quantitative data to analyze. The CQ, therefore, will not be "quick and easy" as with the focus group's reputation (Morgan 1997, p.13). It is time intensive to sit with groups of respondents and listen to them reason and discuss their way through the questionnaire. To do this with a sufficiently large sample size will likely take much longer than conducting a handful of focus groups.

\section{Communal Questionnaire Comparison to Qualitative Interview}

The $C Q$ is similar to qualitative interviewing in that it also allows experiences to be understood in context and aims to capture the voice of participants (Creswell 2015). The CQ continues in the qualitative tradition that believes knowledge is "situated and contextual" (Mason 2002, p. 62).

The $C Q$ also has similarity to larger group interviews or focus groups. Mason (2002) encourages "stimulating interaction of particular kinds through group or focus group interviews, where you guide group discussion through a particular set of topics so that you can observe how situational interactions take place, and how issues are conceptualized, worked out and negotiated in those contexts" (p. 64). My experience underscores the kind of freedom and adaptability of methods to the context that Mason advocates.

The $C Q$ differs from a qualitative interview in that its objective is to continue using a structured schedule and generate quantitative data. The $\mathrm{CQ}$ has a more etic bias, as many items are presented to the informant. As the informant responds, she responds to the items made by the researcher.

The intention is of course not that the $C Q$ takes the place of the qualitative interview or is superior. For example, I utilized a questionnaire only after extensive qualitative interviewing. The emerging themes from the qualitative interviews were used to design the questionnaire. The $C Q$ produces another layer of data available for analysis. This experience led me to realize the merits of a convergent mixed method design (Creswell 2015), where the researcher collects both quantitative and qualitative data, analyzes both data sets, and then merges and compares the results. The $C Q$ goes a step further in generating quantitative and qualitative data from the same source, which should then be incorporated into the larger 
design and analysis. I hope that my research experience reveals the dangers of over-reliance on quantitative methodology and the necessity of interpreting all data in light of factors such as cultural and social dynamics. An innovative mix of methodologies is critical for generating knowledge in each diverse context.

\section{Methodological Suggestions for a Community-Oriented Context}

- Take additional time to sit with the local leader(s) and explain the purpose of the research. In many cases this person will decide for the collective, so it is vital to explain honestly and clearly the overall purpose and details.

- Pay particular attention to the ethical aspects of the intended data collection. If respondents are less willing or able to fend for themselves, it is particularly important that the researcher do no harm. In this type of study, the answers are more easily manipulated by the researcher, so the utmost care must be given to collect the data ethically.

- Find ways to embrace the community orientation rather than fight against it. If a developing context works more collectively, observe the process as people are interviewed within their normal social units.

- Consider a hybrid method like the communal questionnaire, where dialogue is encouraged and recorded during the questionnaire. Many informants will struggle to produce a numerical answer, but will provide much richer qualitative data as they discuss their understanding of the items and think out loud about the answer.

- Seek out the silent voices. Even in a community-oriented environment there are invisible people whose stories, opinions, and attitudes should be sought out.

- If a questionnaire is used, limit the number of items, and keep the items as simple and straightforward as possible.

\section{Conclusion}

In conclusion, the researcher seeking to understand attitudes must be cautious that methodology does not ignore the peculiarities of each culture. The context cannot always be manipulated to fit into our methodology. I completely agree that "It should be evident that one cannot divorce the practice of data collection from the physical and social environment within which data are collected" (Barrett and Carson 1997, p. 5). Turan (1975) argues that conducting survey research requires devising 
methods based on the parameters of the field situation and the ingenuity of the researcher. In order to overcome the challenges and peculiarities of every context, innovative methods that provide new ways of learning about social contexts will be necessary.

Based on a case study of one community-oriented culture in Turkey, I found that a traditional questionnaire that holds the individual opinion as the unit of analysis was inadequate. As the employees at the farm insisted on answering the questionnaire in groups, discussed aloud their communal answers, and struggled to pinpoint an answer expressed in degrees, I realized that I needed to adjust my methodology to fit the context. What emerged was the $\mathrm{CQ}$, a hybrid of a questionnaire, qualitative interview, and focus group. What I am proposing is a synthesis alternative (Hudson and Ozanne 1988) in some sense, because it is a means of collecting both quantitative and qualitative data simultaneously. However, because the data is analyzed iteratively, it is also a dialective alternative (Hudson and Ozanne 1988). The proposed CQ is not a claim to a best world view, but rather another tool for understanding by utilizing multiple research strategies. The quantitative researcher should consider the context and a unit of analysis beyond the individual. My experience corroborates the value in an applied epistemology that integrates both quantitative and qualitative knowledge (Campbell 1988).

In future research, the viability of the $\mathrm{CQ}$ should be tested in different contexts and in different variations. I only used the $C Q$ in a single case study, in a particular time and space, and therefore it needs to be evaluated elsewhere. Are there community-oriented cultures in developed countries that would be well suited for the CQ? Conversely, are there developing contexts in which cultural differences favor more traditional research methodologies?

Future research can also facilitate refinement of the $\mathrm{CQ}$. For example, researchers should consider the ideal number of respondents in a group. Three to four respondents seemed about right for my context, but may vary by the size of the natural social groups and the amount of assistance respondents require. A statistical basis for the size of the sample required to do comparisons between groups that completed the $\mathrm{CQ}$ together is another area of future research. The qualitative and quantitative comparison of the difference in results between a questionnaire completed one-on-one versus the $C Q$ in a group is likewise a topic for future study. Since some of the guidelines of standardization are challenged in this method, future researchers should carefully consider issues of reliability and validity. 
Even quantitative methodology that aims at standardization should not disregard the social, political, cultural, and ecological aspects (Dholakia and Atik 2016) that impact the way in which data can be collected. One context in rural Turkey cannot be treated the same as a North American context or even another Turkish context. Each context requires flexibility and methodological innovation in order to gain understanding. 


\section{References}

Arnould, Eric J., Linda Price, and Risto Moisio (2006), "Making Contexts Matter: Selecting Research Contexts for Theoretical Insights," in Handbook of Qualitative Research Methods in Marketing, 106125.

Barrett, Christopher B., and Jeffrey Cason (1997), Overseas Research: A Practical Guide. Baltimore: The Johns Hopkins University Press.

Bickart, Barbara and E. Marla Felcher (1996), "Expanding and Enhancing the Use of Verbal Protocols in Survey Research," in Answering Questions, Norbert Schwarz, Seymour Sudman, eds. San Francisco, CA: Jossey-Bass, 115-42.

Bulmer, Martin (1993), "General Introduction," in Social Research in Developing Countries: Surveys and Censuses in the Third World. 2nd ed., Martin Bulmer and Donald P. Warwick, eds. London, England: UCL Press, 3-24.

Bulmer, Martin and Donald P. Warwick, eds. (1993), Social Research in Developing Countries: Surveys and Censuses in the Third World. 2nd ed., London, England: UCL Press.

Campbell, Donald (1988), “'Degrees of Freedom' and the Case Study," in Methodology and Epistemology for Social Science, E. Samuel Overman, ed. 377-388.

Catterall, Miriam, and Pauline Maclaran (2006), "Focus groups in marketing research," in Handbook of Qualitative Research Methods in Marketing, 255.

Creswell, John W. (2015), A Concise Introduction to Mixed Methods Research. London: Sage Publications.

Dholakia, Nikhilesh and Atik, Deniz (2016), "A Journal for a Fast-Changing World," Markets, Globalization \& Development Review, 1 (2), Article 1.

Diener, Edward, and Rick Crandall (1978), Ethics in Social and Behavioral Research. University of Chicago Press.

Diener, Edward, Robert A. Emmons, Randy J. Larsen, and Sharon Griffin (1985), "The Satisfaction with Life Scale," Journal of Personality Assessment, 49 (1), 71-75. 
Firat, A. Fuat (2016), "The Dynamics of the Local and the Global: Implications for Marketing and Development," Markets, Globalization \& Development Review, 1 (1), Article 4.

Flyvbjerg, Bent (2011), "Case Study," in The Sage Handbook of Qualitative Research, Denzin, Norman K., and Yvonna S. Lincoln, eds. Sage.

Fowler Jr, Floyd J., and Thomas W. Mangione (1990), Standardized Survey Interviewing: Minimizing interviewer-related error. Vol. 18. London: Sage.

Ger, Güliz, and Özlem Sandikci (2006), "Doing Research on Sensitive Topics: Studying Covered Turkish Women," in Handbook of Qualitative Research Methods in Marketing, 509.

Gundlach, Gregory T., Ravi S. Achrol and John T. Mentzer (1995), "The Structure of Commitment in Exchange," The Journal of Marketing, 78-92.

Hofstede, Geert (2001), Culture's Consequences: Comparing Values, Behaviors, Institutions, and Organizations Across Nations. Second Edition, Thousand Oaks CA: Sage Publications.

Holt, Douglas B. (1994), "Consumers' cultural differences as local systems of tastes: A critique of the personality/values approach and an alternative framework," in AP-Asia Pacific Advances in Consumer Research, Joseph A. Cote and Siew Meng Leong, eds. Volume 1.

Hudson, Laurel Anderson, and Julie L. Ozanne (1988), "Alternative Ways of Seeking Knowledge in Consumer Research," Journal of Consumer Research, 14 (4), 508-21.

Janis, Irving Lester (1982), Groupthink: Psychological studies of policy decisions and fiascoes. Cengage Learning.

Javeline, Debra (1999), "Response Effects in Polite Cultures: A Test of Acquiesce in Kazakhstan," Public Opinion Quarterly, 63, 1-28.

Kitzinger, Jenny, and Rosaline Barbour (1999), eds. Developing Focus Group Research: Politics, Theory and Practice. London: Sage.

Krosnick, Jon A. (1991), "Response strategies for coping with the cognitive demands of attitude measures in surveys," Applied Cognitive Psychology, 5 (3), 213-36.

Krueger, Richard A. and Mary Anne Casey (2000), Focus Groups: A Practical Guide for Applied Research. Los Angeles: Sage. 
Kuzel, Anton J. (1992), "Sampling in Qualitative Inquiry," in Doing Qualitative Research, Benjamin Crabtree, and William L. Miller, eds. Sage Publications.

Lenski, Gerhard E., and John C. Leggett (1960), "Caste, Class, and Deference in the Research Interview," American Journal of Sociology, 65 (5), 463-67.

Mason, Jennifer (2002), Qualitative Researching. Sage.

Miller, Tina and Linda Bell (2002),"Consenting to What? Issues of access, gate-keeping and 'informed' consent." in Ethics in Qualitative Research, Tina Miller et al. eds. London: Sage, 53-69.

Mitchell, Robert Edward (1993), "Survey Materials Collected in the Developing Countries: Sampling Measurement and Interviewing Obstacles to Intranational and International Comparisons," in Social Research in Developing Countries: Surveys and Censuses in the Third World. 2nd ed., Martin Bulmer and Donald P. Warwick, eds. London, England: UCL Press, 3-24.

Morgan, David L. and Margaret T. Spanish (1984), "Focus Groups: A new tool for qualitative research," Qualitative Sociology, 7 (3), 253-70.

Morgan, David, L. (1997), "Focus Groups as Qualitative Research," in Qualitative Research Methods Series, 16, Sage.

Narayan, Sowmya, and Jon A. Krosnick (1996), "Education Moderates Some Response Effects in Attitude Measurement," The Public Opinion Quarterly, 60 (1), 58-88.

Rudolph, Lloyd, and Susanne H. Rudolph (1958), "Surveys in India: Field Experience in Madras State," The Public Opinion Quarterly, 22 (3), 235-44.

Sapsford, Roger (2006), Survey Research. London: Sage.

Shultz, Clifford J. (2016), "Marketing an End to War: Constructive Engagement, Community Wellbeing, and Sustainable Peace," Markets, Globalization \& Development Review, 1 (2), Article 2.

Sunderland, Patricia L., and Rita M. Denny (2007), Doing Anthropology in Consumer Research. Oxford: Routledge.

Tadajewski, Mark (2016), "Focus groups: history, epistemology and nonindividualistic consumer research," Consumption Markets \& Culture, 19 (4), 319-45. 
Tourangeau, Roger, Lance J. Rips, and Kenneth Rasinski (2000), The Psychology of Survey Response. Cambridge University Press.

Truman, Carole, Donna M. Mertens, and Beth Humphries (2000), Research and Inequality. London: UCL Press.

Turan, İlter (1975), Survey Research in a Developing Country: Field Work in Turkey. Comparative Legislative Research Center, University of lowa.

Venkatesh, Alladi (1995), "Ethnoconsumerism: a new paradigm," in Marketing in a Multicultural World. Ethnicity, Nationalism, and Cultural Identity, Janeen A. Costa and Gary J. Bamossy, eds. London: Sage, 26-67.

Watson, Forrest, and Ahmet Ekici (2017), "Well-being in Alternative Economies The Role of Shared Commitments in the Context of a Spatially-Extended Alternative Food Network," Journal of Macromarketing. 